\title{
Modelos híbridos en la arquitectura oriental romana: el ejemplo del templo de Bel (Palmira, Siria)
}

\author{
Hybrid models in Eastern Roman architecture: the example of the \\ temple of Bel (Palmyra, Syria)
}

Sergio España-Chamorro*

Resumen: La hibridación cultural en la ciudad romana de Palmira es una de las cosas más evidentes que el viajero tanto antiguo como contemporáneo puede sentir. A través de uno de sus hitos arquitectónicos más conocidos, el complejo monumental del templo de Bel, se muestran algunas de las claves de lectura para entender e identificar las diversas pautas culturales que le dieron forma. Este examen se ha centrado en los aspectos sobre su compleja arquitectura y decoración arquitectónica con el fin de llevar a cabo una lectura social que vaya más allá de un estudio técnico y ahonde en aspectos sobre la hibridación religiosa y cultural de la sociedad de la provincia romana de Siria.

\begin{abstract}
Cultural hybridisation in the Roman city of Palmyra is one of the most evident things for the ancient and modern visitor. Through one of the most famous monuments, the sacred complex of Bel, this paper provides any clues of interpretation in order to understand and to identify the cultural keys of its shape. This exam has been centred in some of its complex architecture and architectural decoration. All of this provides a social reading of this temple and go deep in some aspects about religious hybridisation and mixed social culture in the Roman province of Syria.
\end{abstract}

\author{
Palabras clave: \\ Arquitectura; \\ Hibridación; \\ Templo de Bel; \\ Palmira; \\ Siria romana.
}

\section{Keywords:} Architecture; Hybridisation; Temple of Bel; Palmyra; Roman Syria.

\footnotetext{
" Doctor en Estudios del Mundo Antiguo por la Universidad Complutense de Madrid (España). IdEx Postdoctoral Fellow, Institut Ausonius (Francia, UMR 5607, CNRS, Université Bordeaux-Montaigne, Labex LaScArBx.
} 


\section{Introducción}

modelo centro, provincia, periferia propuesto por Mitchel Marcus (1990) está ahora en crítica por los nuevos enfoques poscoloniales. Antes de esta tendencia, el contacto colonial se veía como un modelo exportador de la cultura desde el centro y en el que la periferia recibía influencias que hacían que la cultura local se desvirtuase y en donde acabásemos encontrando la cultura central importada con algunas "pervivencias" de la cultura local. El poscolonialismo enfoca estos choques culturales como un nuevo punto de vista en dónde no hay un centro en el punto de análisis, sino que la confluencia cultural genera una nueva cultura que sería convergencia de ambas, desterrando así la idea de una cultura dominante con elementos retenidos de las culturas dominadas, dónde Roma se pone siempre como foco difusor para datar y ordenar tipológicamente el resto de la cultura material romana (JIMÉNEZ DÍEZ, 2018; 2011). Este nuevo enfoque desvirtúa ese modelo disolviendo el concepto de periferia. Esta corriente ha reconceptualizado la visión de los espacios coloniales de época romana hasta el punto de plantear una revisión crítica del vocabulario empleado con el fin de renovar su conceptualización o incluso llegar al punto de descartar el término de romanización.

La situación de tierra de paso que Siria ${ }^{1}$ ha ejercido en la geografía de Oriente Medio, como puerta de Asia Menor, ruta obligada hacia Egipto y África, y punto de unión con Mesopotamia y la península arábiga hicieron que este desierto fuera un vergel donde ideas, culturas, corrientes artísticas e influjos religiosos propiciasen un crisol de culturas. La conquista y la unificación del conglomerado de varios territorios en una única entidad administrativa romana se hizo cada vez más inevitable desde la visión imperialista de Roma y en ese espacio se produjeron esos procesos de hibridación ya indicados en los que la cultura material e inmaterial eclosionó en un modelo social administrativamente inserto en la ecúmene romana, pero socialmente dependiente de todo su trasfondo y devenir histórico.

Motivada por esta posición geográfica, su trasfondo étnico de gran complejidad se conformaba en una amalgama de pueblos semíticos junto con una paulatina penetración de poblaciones árabes nómadas en origen (SARTRE, 1994, p. 337). La lengua común de estas poblaciones fue el arameo, aunque se han documentado numerosas diferencias dialectales propias de microrregiones destacando el nabateo, el palestino, el edeso-sitio y el palmirano (ESPAÑA-CHAMORRO, 2015). Esta confluencia étnica y lingüística propició

\footnotetext{
${ }^{1}$ Una síntesis de Siria como provincia romana puede verse en Rey-Coqyais (1978, p. 45-73). Para la provincia durante el reinado de Vespasiano, vid. Bowersock (1973, p. 133-140). Para las interacciones culturales entre Palmira y Siria en Seyrig (1950, p. 1-7).
} 
que igualmente las manifestaciones de la región fuesen múltiples y complejas, creando situaciones de contacto e hibridismo que caracterizarían igualmente su arquitectura sagrada. A ello se suma el griego como lengua vehicular desde la configuración de los reinos helenísticos y, junto a ella, el latín como lengua de la administración romana.

\section{La arquitectura oriental romana: entre Roma y las provincias}

Moviéndonos a un panorama muy distinto, llegamos a la Alemania de la década de 1950. El patrimonio arquitectónico alemán había sido borrado del mapa tras la II Guerra Mundial. Motivado por la situación que le tocó vivir, el filósofo Martin Heidegger escribió una reivindicación sobre el entendimiento de construir lo que se habita. En dicho ensayo, Heidegger expuso sus planteamientos sobre la construcción, la cual no es un elemento sin más y carente de importancia, sino que se "coaliga" con otros elementos metafísicos que la visión posmoderna ha desvirtuado, pero que son, en verdad, los elementos base dónde la arquitectura toma su sentido y su contexto (HEIDEGGER, 1951). Un edificio no es sólo un lugar, sino también el espacio alterado y generado por su presencia a las que se le supone un porqué tanto en cuanto a la percepción de movimiento y de impacto visual (MAÑANA, 2003, p. 177-178). La construcción queda determinada por su ubicación y su producción y está condicionado por la reflexión anterior y posterior que conlleva y ha conllevado, además de estar intrínsecamente conectado a las situaciones culturales y la coyuntura socioeconómica del mismo, de manera consciente o inconsciente. En esta intersección es dónde se perciben ciertos aspectos presentes en la arquitectura sirioromana, que, sin una consciente intencionalidad aparentemente romana, sirvieron de mecanismo de traslación de aspectos intrínsecos e íntimos de la situación sociocultural de ese momento. Así, numerosos elementos de una arquitectura canónica planteada por Vitrubio $^{2}$ desde las provincias occidentales se funden y reinventan de una manera propia para crear una arquitectura híbrida establecida desde, por y para una cultura híbrida.

Así, las implicaciones orientales (más que sirias) pueden verse en determinados elementos constructivos de la antiguamente llamada arquitectura barroca romana (nomenclatura hoy en desuso, aunque puede encontrarse así citada en obras antiguas: PANE, 1935; CESCHI, 1941; LYTTELTON, 1988). Esta conjunción de elementos orientales

\footnotetext{
2 Sería absurdo pensar en Vitrubio como la estandarización de toda la arquitectura occidental romana obviando sus características provinciales y regionales, cosa que por otro lado ya han superado los estudios en este ámbito, pero su tratado sirve para tomarlo como una directriz general que permita situar el punto de partida para la comparación con los procesos de arquitecturas híbridas en el Oriente romano.
} 
junto con los propios de la arquitectura romana es ejemplo de lo que Wölfflin denomina como atectonismo. ${ }^{3}$

Pero la repercusión cultural es ambivalente. También se importaron determinados modelos arquitectónicos orientales que se divulgaron por la península itálica y que fueron apreciados de diversas formas: por un lado, hubo un uso real de motivos orientales utilizados directamente en la arquitectura áulica romana (palmetas, frisos de leones, ciertas combinaciones de arquitrabes) que principalmente se difundieron a inicios del siglo II d.C.; por otro, hubo previamente cierta apreciación de la arquitectura oriental de manera ficticia con la evocación de arquitecturas pintadas, preminentemente en los frescos del llamado segundo estilo pompeyano a mediados del siglo I a.C. con la incorporación de elementos extendidos en la arquitectura de Oriente Próximo (tales como el llamado frontón sirio, frontón partido o frontón de volutas o columnas entorchadas o sobre podio, por poner algunos ejemplos).

En el siglo I d.C., en el inicio del Imperio, el uso de estructuras no relacionadas con administración, producción o habitabilidad tales como arcos de triunfo o pórticos ornamentales permitió el cada vez mayor empleo de tratamientos arquitectónicos monumentales que rompieran la linealidad mantenida hasta la tardorepública. Sin embargo, su extensión no se produjo de manera amplia debido, quizás, a motivos heterogéneos, primando sobre todo el gusto proarcaico y clasicista que se impone en la arquitectura augustea, gusto que recogerá Vitrubio en su tratado De Architectura. Fue definido por Boethius como un clásico activo que luchaba contra lo que consideraba un estilo equivocado y contra las confusas reglas de gran parte de la arquitectura y el arte helenístico (BOËTHIUS; LING; RASMUSEN, 1978, p. 14 y ss.).

Durante el siglo I d.C.y más concretamente en época flavia, un relativo estancamiento de innovaciones arquitectónicas y un Oriente con una lenta recuperación agrícola tras las Guerras Civiles (BALL, 2001), la influencia oriental en la caput mundi no tendría gran impacto. A finales de este siglo, cierta recuperación permitiría iniciar proyectos ambiciosos, destacando por encima de todos ellos la acrópolis de Baalbek, a pesar de que su periodo constructivo abarcase hasta el siglo III, pero entendiendo que todo el complejo ya había planteado conjuntamente desde su inicio (ESPAÑA-CHAMORRO, 2015).

Este desequilibrio de factores tradicionales sobre la arquitectura imperial desembocó en una real apreciación visible en la arquitectura áulica, alcanzando su punto álgido con

\footnotetext{
${ }^{3}$ Wölfflin (1950, p. 149) indica, para el estudio del arte dos conceptos importantes: el tectónico, que sería "el estilo del estricto conformismo y de la total adhesión a la norma" y el atectónico que sería "el estilo de adhesión más o menos oculta, a la norma y del ordenamiento libre", pero teniendo en cuenta que el atectónico refleja siempre, en sí mismo, la tradición del tectónico.
} 
el arquitecto principal de los programas edilicios de Trajano: Apolodoro de Damasco, uno de los escasos ejemplos de nombres de arquitecto conocidos y figura de la imagen arquitectónica que se vincula a dicho emperador. El interés por la arquitectura oriental también se vería perpetuado durante el reinado de Adriano. Es desde esta época cuando vemos cómo se reactiva el flujo cultural bidireccional, también visible en la expansión de los cultos orientales por el Mediterráneo.

¿Qué modelo de arquitectura llegó a constituirse en Siria? Los modelos implantados en dicha provincia romana dejaban ver determinados elementos de la arquitectura itálica, pero sin abandonar formas, estructuras y elementos decorativos usados antes de la llegada de griegos y romanos. Así, elementos estructurales se reinterpretan de manera decorativa (podios, columnas, frontones), y los propios elementos decorativos ya usados se reinterpretan (capiteles, fustes, molduras), combinando todo ello con elementos propios de la arquitectura prerromana de origen semita, que sobre todo se mantiene en la edilicia sacra por identidad, pero también por funcionalidad ritual.

\section{El templo de Bel en Palmira, arquetipo de hibridación}

Habiendo expuesto los puntos básicos del planteamiento de este estudio, he tomado de templo ${ }^{4}$ de Bel en Palmira, ${ }^{5}$ el espacio religioso más importante de la ciudad para una de las deidades principales de la urbe. ${ }^{6}$ La ubicación del templo se halla en uno de los extremos de la ciudad, sobre una pequeña loma. La conexión con la ciudad se realiza por una vía columnada, denominada como via sacra que conecta dicho templo con el recinto funerario más importante de la ciudad (BALL, 2001, p. 256), además de ser el trayecto de una procesión durante el equinoccio de primavera con la imagen del propio Bell llevada sobre un camello (VEYNE, 2009, p. 232), según se aprecia en un relieve (Fig. 1).

\footnotetext{
${ }^{4}$ Según Millar (1993, p. 313), la dedicación de dicho templo fue en el 32 a pesar de que los pórticos y el témenos siguieron construyéndose hasta el siglo II. Dicho templo permanecería en funcionamiento durante la tetrarquía militar y bajo el dominio de Aureliano, en contraposición a otros espacios públicos y templos de la misma ciudad (MILLAR, 1993, p. 182). Posteriormente se reconvertiría en iglesia bizantina.

${ }^{5}$ Sobre sincretismos y asimilaciones anteriores y posteriores a la época romana ver la síntesis que realizaron Richardson (2002, p. 36) y De Jong (2007, p. 4), quienes indicaban que en las ciudades del interior del desierto como Palmira o Dura Europos, la penetración de las pautas culturales helenas no había sido tan global como en la costa. Sobre esta dicotomía Baudini (2010, p. 56) indicaba que, si bien Palmira no fue excepción en plantear su urbanismo a la manera helenística, incorporando un teatro, esta ciudad partía de una realidad difícil de valorar teniendo en cuenta factores que estaban presentes, pero de manera muy limitada tales como el culto imperial (vid. infra), que tenía un papel preeminente en los espacios clave de la ciudad, pero que quedó seguramente adscrito a las élites.

${ }^{6}$ Bel gozaba de preeminencia en la ciudad, pero no hay que olvidar la importancia de Baalshamin para la vida religiosa de la ciudad. Ambas deidades son el reflejo perfecto de hibridación previa a la llegada de los romanos en la zona debido a que estos pertenecen a dos tradiciones religiosas distintas provenientes de dos grupos étnicos diferentes en la fundación de Palmira (BALL, 2001, p. 84).
} 
Figura 1 - Plano de Palmira

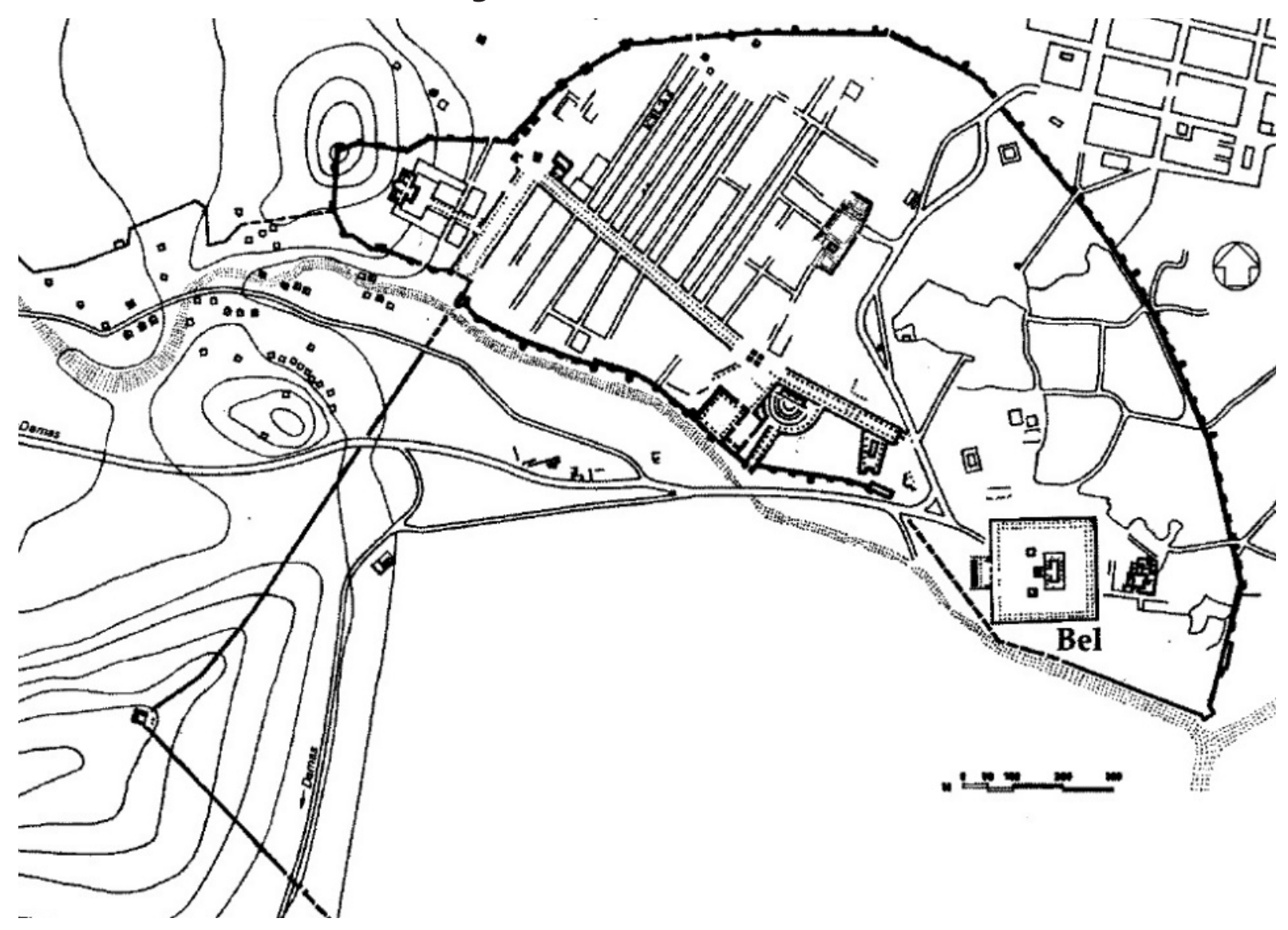

Fuente: Ball (2001).

Sin duda, el templo con más importancia para la vida religiosa de la ciudad de Palmira fue el de Bel. ${ }^{7}$ Dicho templo, estudiado profusamente, es el ejemplo perfecto de hibridación arquitectónica, cultural y, sin duda, religiosa que podemos encontrar en todo el territorio sirio. Este templo suscitaría muchas dudas para un romano que proviniera de las provincias occidentales, pero quizás sería uno de los pocos elementos que seguirían recordando a un romano que aún se encontraba en los límites del Imperio (VEYNE, 2009, p. 227). Ello es debido a que la fusión de elementos arquitectónicos prerromanos se combina de tal forma con determinados elementos de la arquitectura canónica romana (la definida por Vitrubio), que remitía a la arquitectura imperial a pesar de incorporar elementos que a todas luces sorprendiesen por su uso diverso y su forma diferente. Así, el academicismo de los capiteles jónicos y corintios (STAMPER, 2008, p. 68, quien explica el predominio de estos últimos) que adornaban dicho templo, chocaba rápidamente con

${ }_{7}^{7}$ Posiblemente no sería un templo dedicado sólo a Bel sino a una tríada formada por Bel, Yarhibol y Aglibol. Fue postulado por Hammad en relación a interpretaciones de restos epigráficos y cosmologías semitas (HAMMAD, 2005, p. 61-65). 
cuatro factores: una entrada que no era la canónica, los remates almenados, las ventanas, más propias de un edificio civil que religioso, y finalmente un tejado plano (Fig. 2).

Figura 2 - Reconstrucción axonométrica del templo de Bel

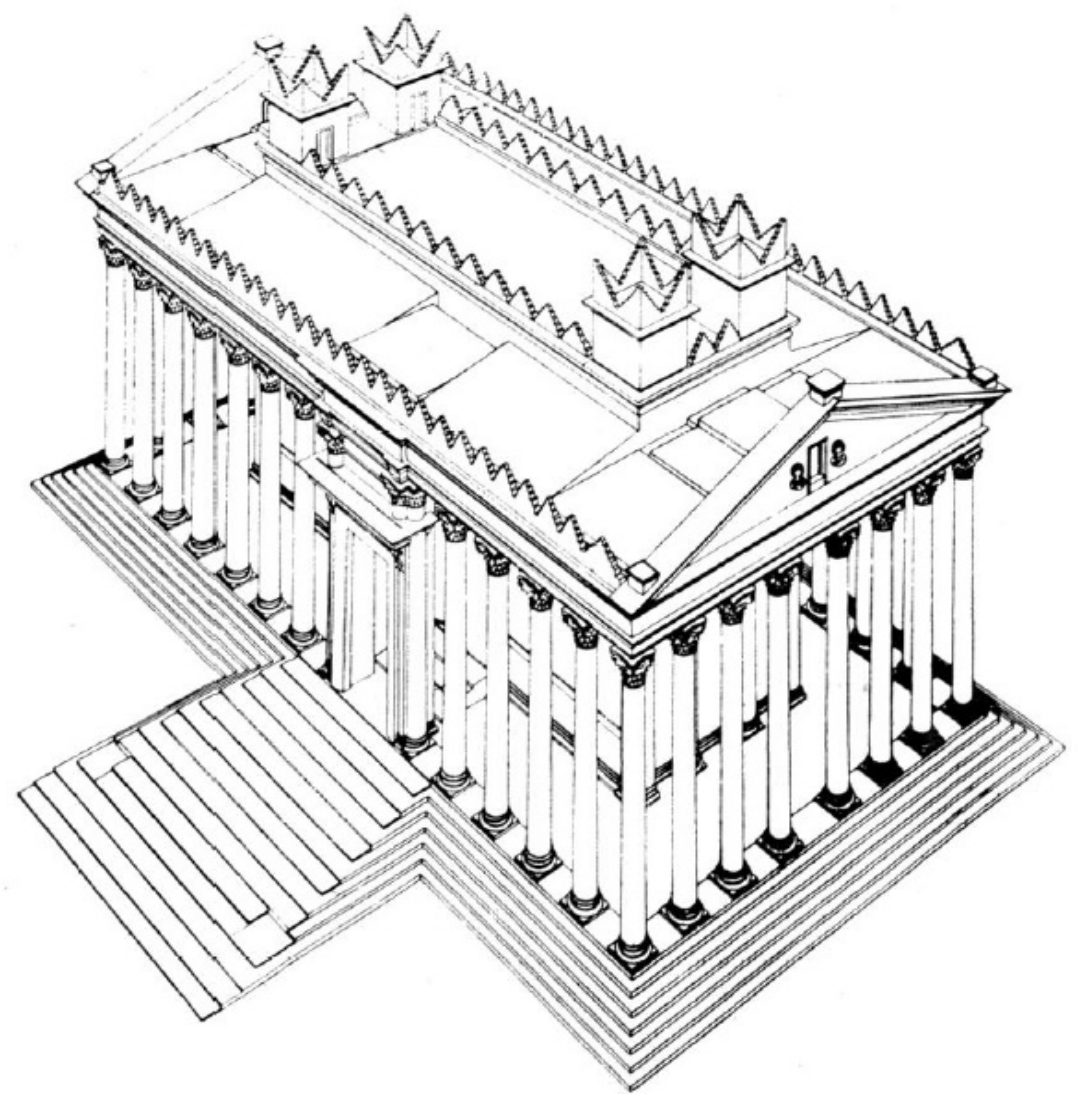

Fuente: Veyne (2009).

Analizando estos factores arquitectónicos, además de la decoración, se puede llegar a contextualizar determinados elementos estudiados de forma separada para intentar llegar a entender el poderoso factor de la hibridación y el encuentro colonial (VAN DOMMELEN, 2007; JIMÉNEZ DÍEZ, 2018; 2011) en Palmira que dio lugar a la composición de este templo.

Con respecto a la entrada, ésta se encuentra situada en su lado más largo y desviado del eje central. Este cambio drástico y deliberado de la planta puede ser debido, como indica Amy, a la adaptación de un templo para dos deidades o dos tipos de rituales, y pone como ejemplo el templo de Venus y Roma (AMY, 1950, p. 98), aunque no obstante dicho templo tiene dos entradas canónicas y, pese a ser dobles, están situadas en el lado más estrecho, premiando la frontalidad escénica de la cella al entrar (Fig. 3). 
Figura 3 - Planta del conjunto del templo

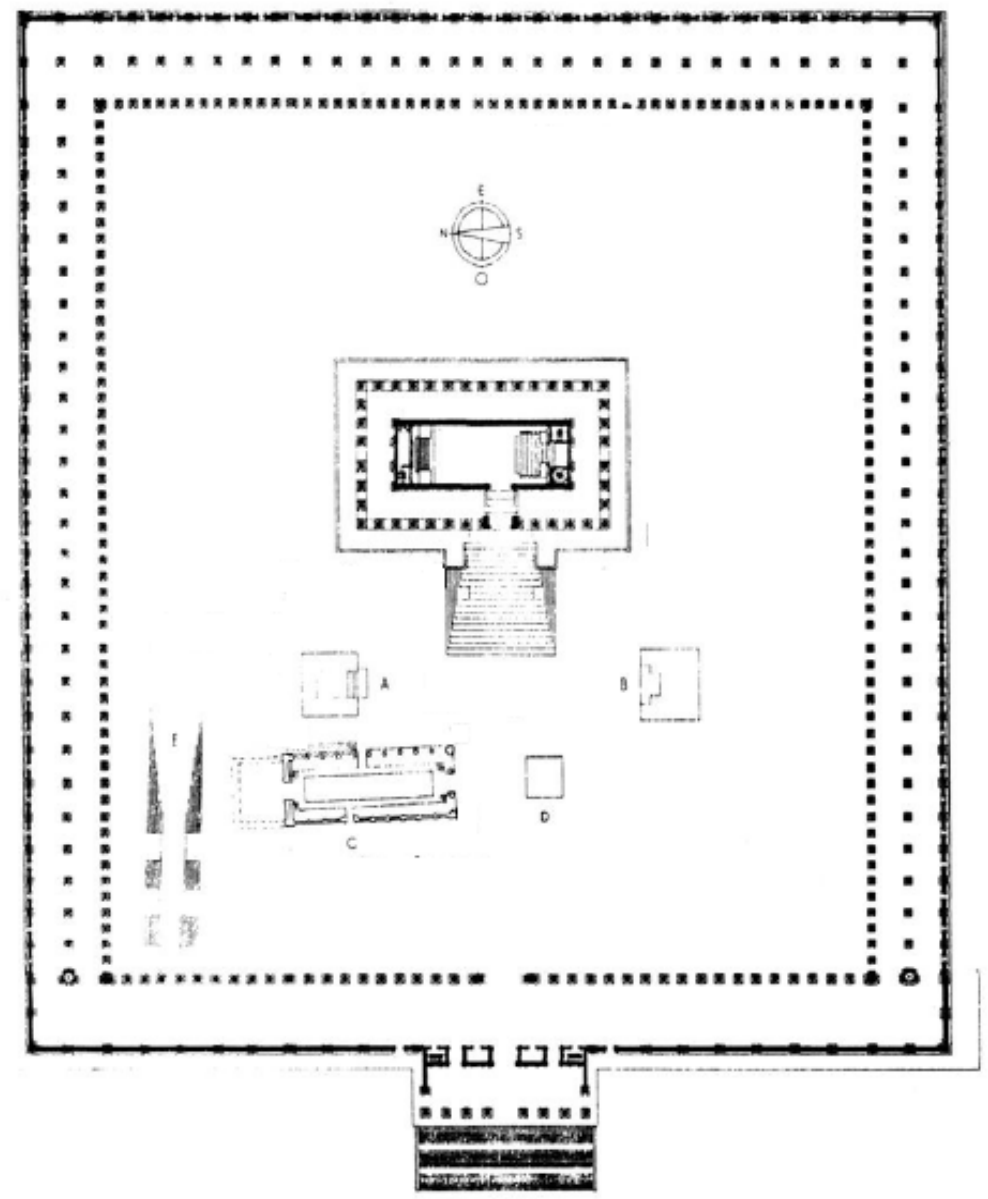

Fuente: Veyne (2009).

Por el contrario, el caso del templo palmirano es más atípico, ya que la entrada se sitúa en uno de los lados largos y está desviada del eje simétrico de dicha fachada. Richmond contrapuso el carácter oriental del plano derivado de las necesidades de un culto semítico (RICHMOND, 1963, p. 43-54), con la decoración helenístico-romana, pero Lyttelton, por su parte, señaló que la importancia de las tradiciones helenísticas de Asia Menor y Alejandría tuvo relativamente más importancia que en Roma (LYTTELTON, 1988). Lo que está claro es que este desplazamiento del eje es deliberado, seguramente como apunta Amy, y estuvo destinado a dejar más espacio para los diversos rituales frente al tálamo norte (AMY, 1950, p. 98), al cual la bibliografía alude por su mayor decoración con respecto al sur, como relativamente más importante.

El segundo punto que llamó la atención a Veyne es el de los remates almenados o merlones (VEYNE, 2009). Éstos se encontrarían en la parte superior de la cornisa del templo $y$, pese a tener una exuberante decoración de corte helenístico, son un elemento atípico en la arquitectura romana o más bien un elemento típicamente oriental. Butcher definió este elemento como una importación del mundo mesopotámico y asirio (BUTCHER, 2011, 
p. 290), ya que dicho elemento se puede ver en palacios y murallas representadas en los relieves. Este contradictorio elemento también se asocia a templos fenicio-púnicos como el templo de Amrit o el santuario de Ma'bed, ambos en la costa siria (PRADOS, 2008, p. 107-108), además de también estar numerosamente presente en contextos funerarios como en el Meghacil B de Amrit (BUTCHER, 2011, p. 106), en contexto fenicio, o en las tumbas 68, 69, 70 y 71 del Siq exterior de Petra, en contexto nabateo (TAYLOR, 2005). ${ }^{8}$

Éste no es el único caso que se puede encontrar este elemento en un contexto romano, ya que es comparable al altar turriforme del templo de Kalat Fakra (TAYLOR, 1986, p. 106), al igual que en el templo de Dmeir (AMY, 1950, p. 84-85) y en la restitución del templo de Slêm propuesta por Amy a partir de los restos de decoración arquitectónica (AMY, 1950, p. 90), donde en ambos casos se remata una techumbre plana con este elemento del mismo modo que lo hace en el de Bel, quedando aún in situ en el de Dmeir. En Palmira esta solución se empleó de forma casi idéntica a la del templo de Baalshamin, donde también está decorado con flores de acanto. Butcher indicó que no se ha llegado a conocer la significación y el porqué de este contradictorio elemento (BUTCHER, 2003). No obstante, hay que valorar las apreciaciones de Veyne (2009) con respecto a la silueta y tener en cuenta la característica imagen que tendría dicho edificio. ${ }^{9}$

La cobertura del templo es una cosa que también choca con los cánones vitrubianos, pues en la arquitectura de las provincias occidentales jamás se hubiera pensado en una techumbre plana para dar solución a la cubierta. La utilización del modelo de coberturas planas para la ubicación de terrazas es nuevamente un elemento arquitectónico prerromano. En los templos fenicios encontramos la solución de terrazas superiores o azoteas como cobertura debido a que los rituales a dichas deidades eran al aire libre y debían efectuarse a la vista de todos los fieles (PRADOS, 2008, p. 144), muy al contrario que numerosos rituales romanos, los cuales se celebraban en el interior de la cella y en los que se preservaba su privacidad. ${ }^{10}$ Existen más ejemplos del uso de azoteas en templos romanos de Siria como son, de nuevo, Dmeir y Slêm. En estos templos, además del de As-Sanamain, se erigieron torres que completaban dicho esquema y que servían

\footnotetext{
${ }^{8}$ Especialmente en la estructuración de esta tumba, Amy veía un modelo precedente de escenografía helenísticonabatea que servirá para la estructuración de Palmira pero, por ende, también de Slêm, Dmeir y seguramente AsSanamain también. Ve como una representación en planos de lo que podría ser o bien la columnata del témenos y el templo o bien unos propileos que preceden al templo (AMY, 1950, p. 104).

${ }^{9}$ El cambio drástico de situar la entrada al Oeste y marcar su eje Norte-Sur responde a un cambio teológico de la concepción astral que se debió de producir en época helenística en toda la región y derivaría de una medida para el movimiento de los cuerpos celestes (HAMMAD, 2005, p. 56).

10 Sólo poniendo un ejemplo, es interesante la inscripción del templo de Apolo en Pompeya (CIL X, $7877=$ ILS 5915 ) que indica que, debido a la construcción de la casa de Triptolemo en las cercanías del templo, su altura sobrepasó el muro original que ejercía de témenos y sus ventanas tenían contacto con el área sacra, por lo que se tuvo que levantar el muro de separación para preservar el entorno sagrado.
} 
de acceso a la terraza superior a través de escaleras interiores. El caso más similar al del templo de Bel de Palmira es el templo de Dmeir. Ambos templos disponen de cuatro torretas decoradas con merlones. Estas supondrían la salida de las escaleras, pero no todas tendrían funcionalidad ya que lo que se pretende es guardar la simetría (SEGAL, 2008, p. 101). Con respecto a las escaleras, Kaizer ha llamado la atención de que los animales empleados para los rituales no podrían ser grandes y pesados debido a las dimensiones de estas (KAIZER 2008, p. 184).

Según Veyne, los templos de Oriente no son los relicarios o joyeros de Grecia y Roma, sino una vivienda del propio dios (VEYNE, 2009, p. 230) o, como también dice Will, el dios griego se entiende como "un amo de casa bastante democrático" y el dios sirio se entiende como "un soberano oriental" (WILL, 1995, p. 377). Teniendo esto en consideración, se entiende que los templos orientales tengan ventanas, algo sin paralelos en el mundo romano. Este cambio significativo de la concepción del panteón semítico en contraposición a la tradición grecorromana es un punto de discordancia que, lejos de haber suscitado una confrontación cultural, supuso una adaptación que propició estos modelos de arquitectura híbrida que aquí se analizan.

Volviendo a Palmira, es notable señalar que ya existía un santuario a Baal en el siglo II a.C. donde se restauró o, más bien, rehízo el que vemos hoy en día, así como otros santuarios que se fueron restaurando paulatinamente en la ciudad, como el de Baalshamin. En esas restauraciones se mantienen muchos de esos elementos enumerados dentro de su nueva estructura. Otras características discordantes de dicho edificio se pueden percibir en su estructura principal. Ésta no se diferencia en tamaño, ya que las medidas son bastante similares a otros templos de la ecumene romana como la Maison Carrée de Nimes o el del Menandro en Turquía y está lejos de parecerse a otros grandes complejos de Asia Menor y Oriente como el de la Artemis Efesia o el vecino templo de Baalbek en Líbano, en la misma provincia, pero de medidas colosales (ESPAÑA-CHAMORRO, 2015). El templo de Bel tiene 8 columnas en su lado corto y 15 en los largos. De su planta se ha postulado que podría ser producto de sucesivas modificaciones a lo largo de su historia (VEYNE, 2009, p. 232). La puerta del peristilo ha sido fechada en el siglo I d.C., aunque los tálamos interiores corresponden al siglo II d.C., si bien las molduras que se usan en ambas partes dan la prueba de que son contemporáneas, ya que en el siglo II esa misma decoración cambia en todos los edificios públicos de Palmira donde se usan.

Con respecto a los capiteles, éstos tienen forma de cono truncado desnudo, pero no siempre estuvieron así. Se documentaron restos de la cubrición de bronce dorado (cuyo cálculo se ha estimado en un total de 21 toneladas) que debió de tener seguramente orden corintio (HAMMAD, 2005, p. 33). Los muros de la cella tienen pilastras adosadas 
(Fig. 4), una característica realmente común en los templos sirio-romanos, y los muros norte y sur tienen dos semi-columnas jónicas rematadas por capiteles nada canónicos que imitan un entablamento en 5 franjas. Hammad propuso que estas columnas jónicas hubieran estado enmarcadas en señal de preminencia al corintio (HAMMAD, 2005, p. 35), paralelismo que vuelve a cumplirse en el interior de la cella, más concretamente en el tálamo norte.

Figura 4 - Entablamento de la fachada principal y detalle de capitel de pilastra imitando el esquema del entablamento

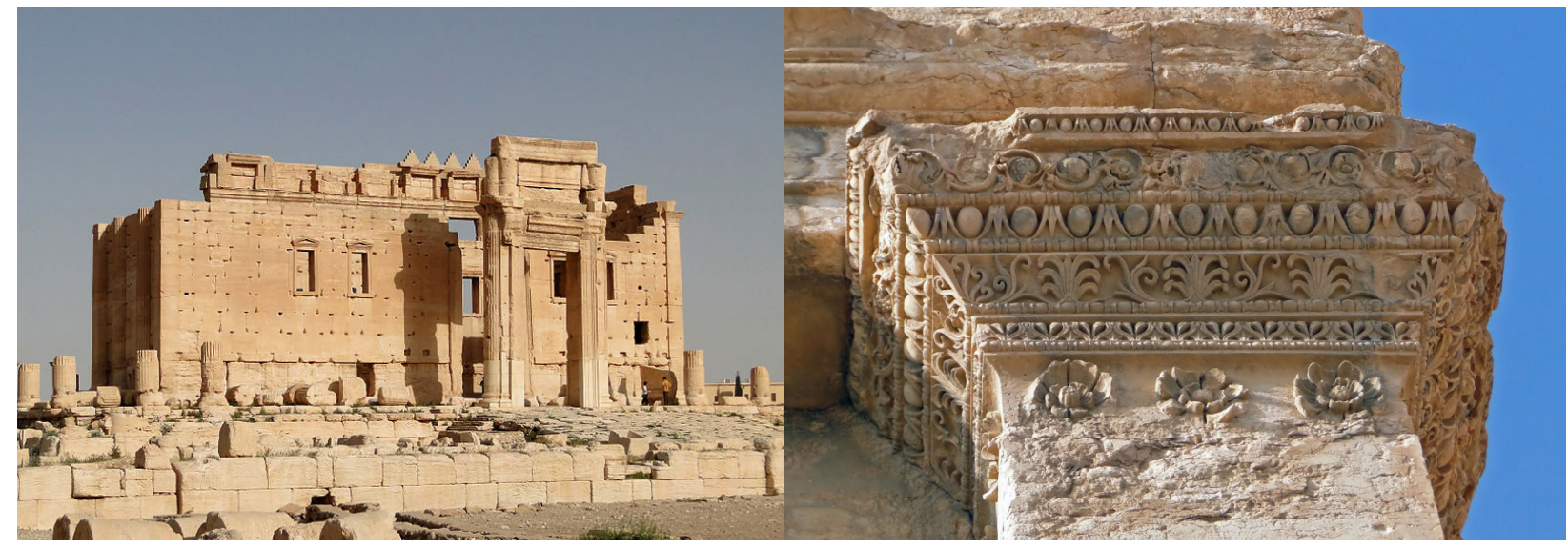

Fuente: Cortesía de Jorge García Sánchez.

Sobre los capiteles y el entablamento se encuentra un friso decorado con una cenefa floral de tallo ondulante. Encima de ésta se halla una cornisa con una doble franja de dentículos que acaban en una cyma reversa muy desgastada, pero muy característica, pudiendo encontrarse numerosos ejemplos por todas partes del templo. Ésta tiene una forma arqueada formando en su parte superior unas oquedades periformes. Es la misma gola que el templo redondo del Foro Boario, lo que hizo que Ward-Perkins propusiese un origen asiático de este último (WARD-PERKINS, 1976). También hay ejemplos parecidos en el Templo de Atenea en Magnesia y el de Hécate en Laginia. Este modelo de cyma no se encuentra en otros edificios posteriores de Palmira encuadrándose la primera en el siglo I d.C. Se puede ver también en los tálamos norte y sur, lo que me motiva a pensar que son coetáneos, ya que en el siglo II d.C. la cyma usada en edificios públicos de Palmira cambia de forma. El astrágalo entre devanaderas de algodón tiene forma globular y es también característico del templo (incluidos los tálamos) pero no en otros edificios públicos posteriores. Esto denota que la puerta y los tálamos pertenecerían a finales del siglo I d.C. (LYTTELTON, 1988, p. 141-142). 
Pasando a ver la anómala entrada principal, la cual no está situada en el centro de la fachada, puede vincularse la articulación de las fachadas de los templos ptolemaicos y más concretamente el esquema que enmarca la puerta de entrada entre dos columnas directamente adosadas a los dinteles que formarían la puerta (LYTTELTON, 1988, p. 143; BALL, 2001, p. 337). El caso del templo de Bel en Palmira es un paralelo bastante cercano a otros templos ptolemaicos, pero, en mi opinión, debe entenderse como una evolución local, ya que pensar en una importación del modelo desde Egipto sería algo forzado y a todas luces descartable. No obstante, no hay que olvidar que la arquitectura ptolemaica, a excepción de Alejandría, mantiene en los templos un modelo de construcción más próximo a los preceptos arquitectónicos egipcios, guardando su esencia e identidad constructiva, y no se importa a otros templos clásicos de Oriente Medio.

La dicotomía entre romano y oriental es posible de apreciar en todo el edificio (SEYRIG, 1934, p. 184-185), pero no obstante hay que tener en cuenta la necesidad de algunos elementos para adaptarse a las necesidades imperantes en los cultos locales. La utilización de elementos indudablemente clásicos derivados del helenismo se mezcla y aplica a elementos que no tienen paralelismo en el mundo clásico occidental y el ejemplo más claro es el uso de pequeños frontones en las ventanas de la cella. En el mundo romano no hay otras referencias a este uso; si acaso se puede señalar la utilización de hornacinas interiores destinadas principalmente a decorarse con estatuas, pero nunca ventanas como tal.

Con respecto a la decoración de estos dinteles, hay precedentes de esta suntuosidad plástica en los templos nabateos como podría ser el de Baalshamin en Sì. También se puede apreciar un esquema que, sin ser igual, guarda paralelos de esta decoración en algunos templos del Monte Hermón, donde hay franjas aplicadas al marco que tienen el mismo estilo (como los templos de Antourna y Ksar Naous, vid. TAYLOR 1986, p. 116-117, 121 y ss.). La entrada monumental está ricamente decorada con hojas de olivo, parra y flores. Las columnas del peristilo estuvieron decoradas con hojas de metal dorado tal y como lo motivan los agujeros para apliques (LYTTELTON, 1988, p. 143). En las antas del muro también habría habido rosetones, ambos de corte helenístico.

Los lados de las vigas del peristilo están esculpidos con motivos florales y con figuras que muestran los ritos del templo (VEYNE, 2009, p. 232). Seyrig vuelve a confrontar estilos señalando la orientalización de la escena con el estilo clásico de representación y los motivos florales (SEYRIG, 1934, p. 184-185). Estos elementos decorativos de la cornisa son, según postula Hamman, de indudable sustrato pergameneo (HAMMAD, 2005, p. 33).

Con la extensión del templo de época romana, más amplia que en la fase anterior, se puede ver como el perímetro englobado por el témenos necesitó un recorte 
generalizado y aterrazado del patio para nivelar el terreno general del témenos. Sobre este aterrazamiento se asentó el podio del templo y sobre éste se peraltan los dos tálamos: el norte a $62 \mathrm{~cm}$ y el sur a $48 \mathrm{~cm}$.

El pórtico tiene un esquema 8 × 15 con doble intercolumnio, ${ }^{11}$ pero en él las columnas son demasiado elevadas con una altura de 58 codos, 14 entre ejes y 9 entre columnas, $^{12}$ lo que lo sitúa entre los estilos picnóstilo y sístilo definidos por Vitrubio (en los templos picnóstilos la anchura de la columna es $1 / 10$ parte y en el sístilo de 1/9). Estos datos inducen a proponer que la ejecución técnica del proyecto recayó en un arquitecto romano o que conocía el sistema modular romano. Esto también es perceptible en los patios del templo, ya que no eran un refugio para el sol, sino que al igual que en Occidente, ahora sí copian ese modelo de comercio dentro del témenos del templo. La adaptación de determinados usos religiosos se combina de manera funcional con determinadas características importadas de occidente propiciando una conjunción cultural patente en estos aspectos edilicios.

Pasando a analizar el interior del templo se observa una estructura dividida en dos adyta los cuales finalizan en un tálamo monumental. La fachada del tálamo norte está a una altura bastante alta y rodeada de peldaños. La estructura de este adytum tiene una estructura en tres partes: un vano central que ocupa la mitad del espacio y unos vanos laterales proporcionalmente mucho más pequeños. El vano central repite el esquema de la puerta de entrada, se enmarca entre columnas adosadas al muro, repitiendo nuevamente el esquema que recuerda al modelo ptolemaico. En este caso, si nos fiamos de la reconstrucción (Fig. 5) que Wiegand hizo de este tálamo (WIEGAN, 1932), quien lo vio en mejores condiciones a principios del siglo XX (ya que la decoración en esta parte estaba muy dañada ya a inicios del siglo XXI y actualmente perdida después de la destrucción del templo), se puede ver como dos columnas jónicas se solapan y superponen, dando la sensación de una doble voluta en los extremos.

\footnotetext{
${ }^{11}$ Dimensiones del estilóbato: 30,05m x 55,6m. Dimensiones del pódium: 38,85m x 65,54m

12 Hammad (2005, p. 31) siguiendo la obra de Seyrig (1937; 1954), Ammy (1950) y Will (1995) usa al igual que ellos la medida del codo babilónico $(27,25 \mathrm{~cm})$, medida que postulan como la que se empleó en la elaboración del templo. Así 58 codos son $15,81 \mathrm{~m}, 14$ codos son $3,81 \mathrm{~m}$ y 9 codos son $2,45 \mathrm{~m}$.
} 
Figura 5 - Fachada interior norte. Reconstrucción de T. Wiegand

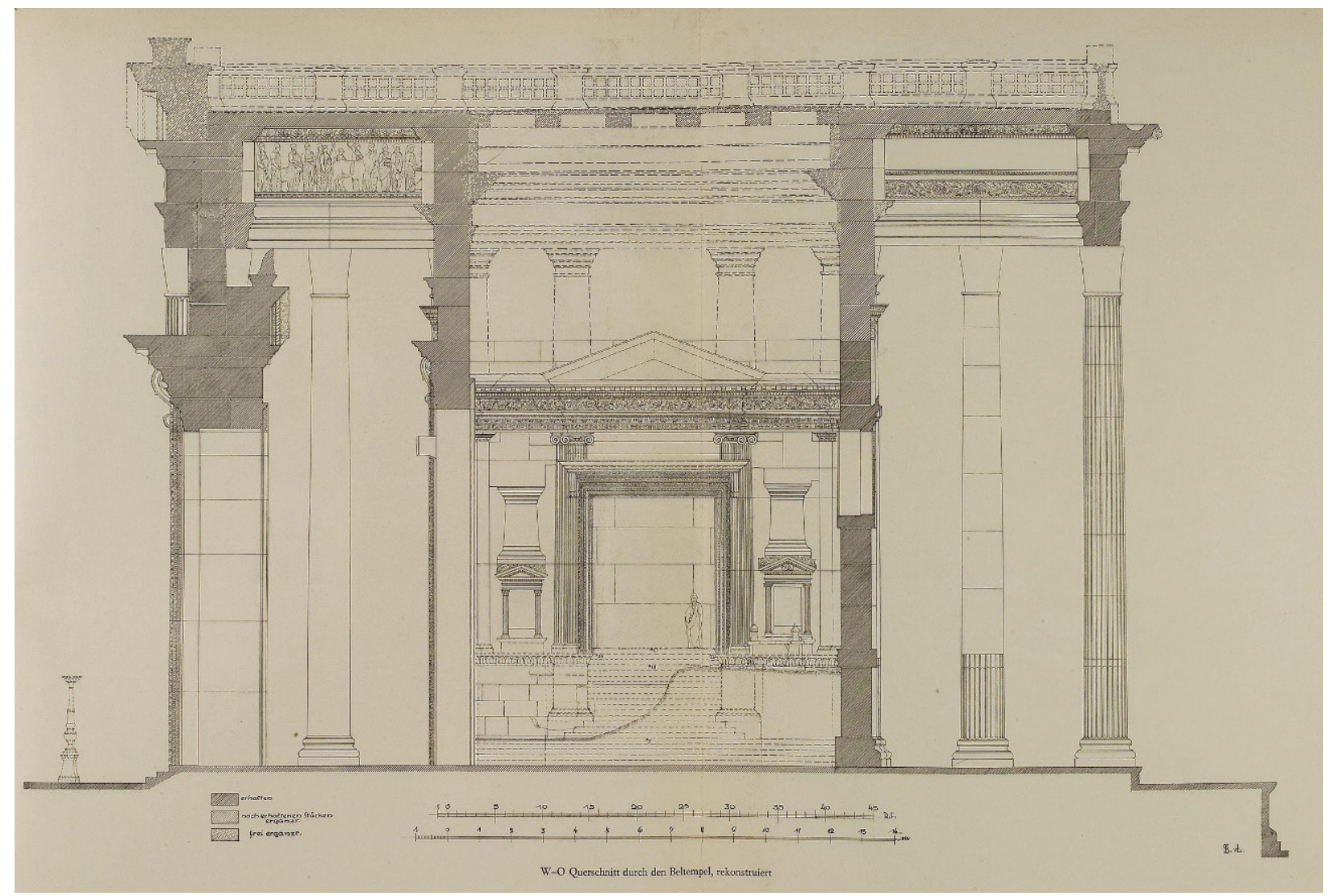

Fuente: Wiegand (1932).

Seyrig en su reconstrucción plantea bastante acertadamente la elevación de las columnas sobre un plinto (SEYRIG, 1934), seguramente basándose en el esquema del tálamo sur (Fig. 6) y, además, teniendo en cuenta que es una característica muy implementada para la escenografía interior de los modelos arquitectónicos sirios. Esto se puede ver en otros templos de la misma provincia como en el interior de la cella del templo de Baco en Baalbek. Además, se puede apreciar cómo el recorrido del entablamento continúa en la parte central y en las pilastras laterales adelantándose sobre éstos y retrotrayéndose en el muro plano, una solución decorativa que encontramos en pocos casos y que nos remite también al mismo esquema interior de las columnas adosadas al muro de la cella del templo de Baco en Baalbek (ESPAÑA-CHAMORRO, 2015). 
Figura 6 - Techo del tálamo sur

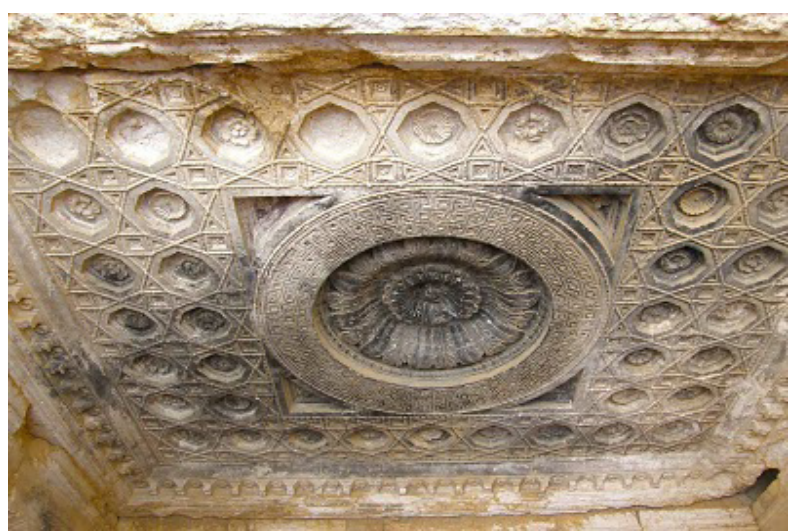

Fuente: Cortesía de Jorge García Sánchez.
Figura 7 - Techo del tálamo norte

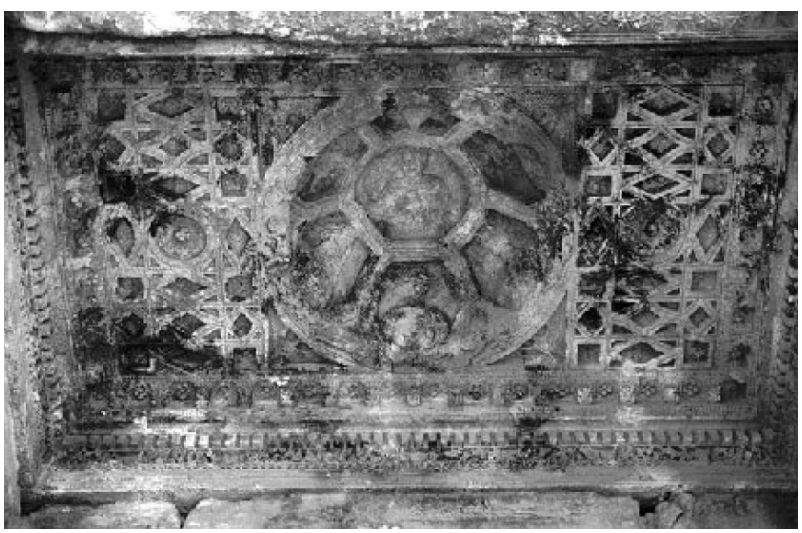

Fuente: Cortesía de Jorge García Sánchez.

El techo del tálamo norte (Fig. 7) está decorado con una representación de siete bustos que podrían interpretarse con los siete planetas: Luna, Marte, Mercurio, Júpiter, Venus, Saturno y Sol. Brown indica la posibilidad de sustituir una deidad y situar a Bel en el medio de estas representaciones (BROWN, 1939, p. 286). Por el tipo de esquema basado en un hexágono central y representaciones interiores, recuerda a la decoración ornamental del techo del peristilo del templo de Baco en Heliópolis, que, aunque con ciertas diferencias de significado, ${ }^{13}$ podría haber sido un paralelo directo y demostraría la vinculación entre ambos complejos sagrados.

Volviendo al tálamo norte, el cual en origen estuvo a la misma altura que el sur (Fig. 8), fue peraltado y se le dispuso una escalera más empinada que, según Hammad (2005, p. 38), a más dificultad señalaría mayor escala de jerarquía. Además, en este espacio interior se da acceso a una prolongación de la sala casi oculta a la vista de quien está en la cella y se dispone hacia el oeste. Al otro lado se halla una escalera cuadrada que al igual que en el tálamo sur, permitía acceder a la azotea.

\footnotetext{
${ }^{13}$ Las diferencias son bastante considerables, ya que uno es parte de la cella, el espacio más sagrado del templo, y el otro está dispuesto en la parte externa. Además, a diferencia de la propuesta de las personificaciones planetarias, Seyrig apuntó que en Baalbek las personificaciones eran ciudades que habían colaborado en la consecución del templo debido a la lectura que hizo en una inscripción de una de estas personificaciones heliopolitanas, definiéndola como ANTIOXIA en Seyrig (1937; 1954, p. 80-98) y España-Chamorro (2015).
} 


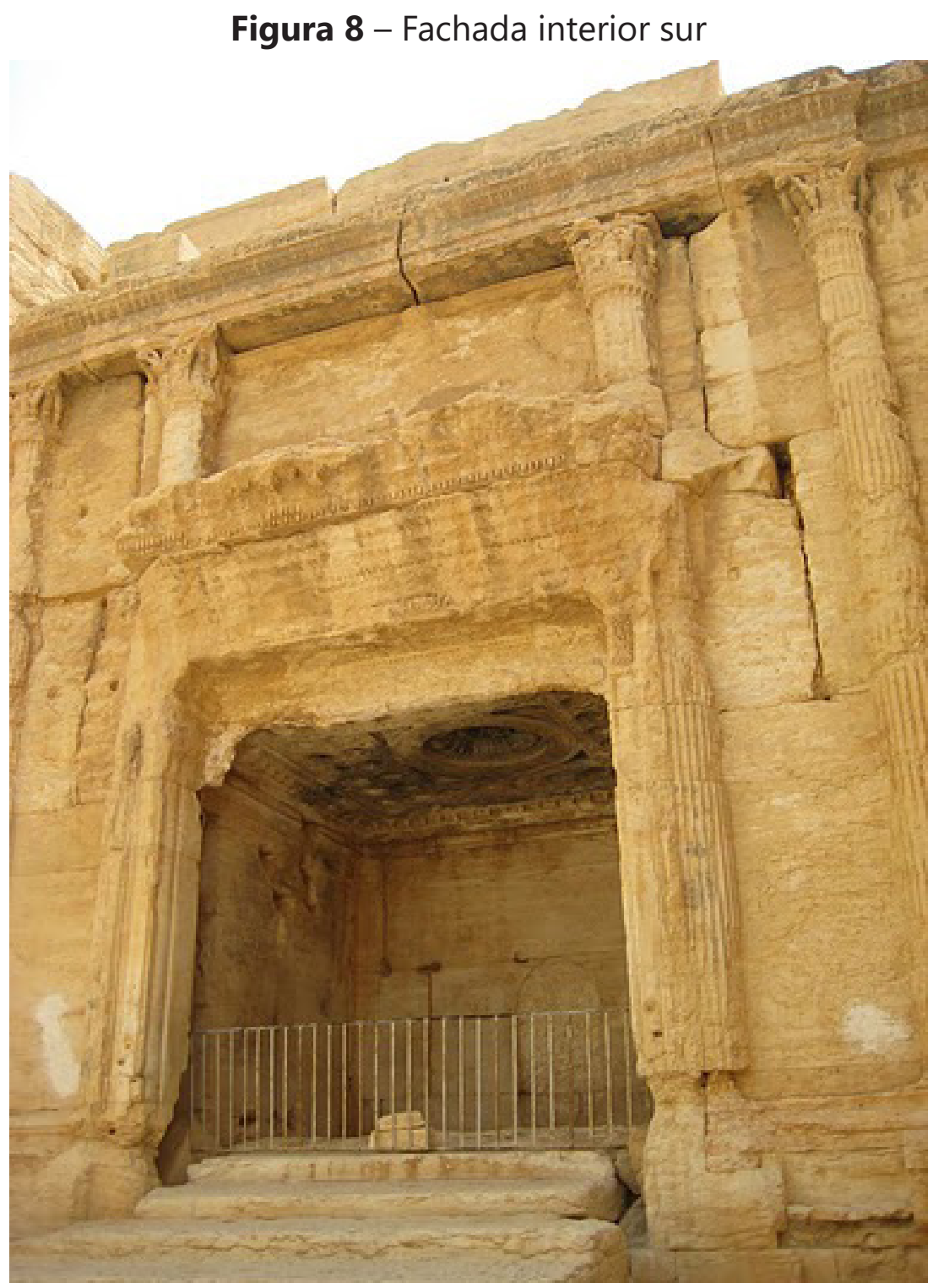

Fuente: Cortesía de Jorge García Sánchez.

Los vanos laterales se encontraban subordinados al esquema: cada uno formaba un nicho enmarcado con columnas corintias de fuste acanalado que sostenían un entablamento y un frontón. Sobre estos parece haber un altar esculpido en bajorelieve. Entre el frontón y el altar hay unas acróteras decoradas como palmetas que podrían recordarnos al friso de los leones del templo de Júpiter en Heliopolis. Toda esta decoración que no es desconocida en las provincias occidentales llama la atención por su disposición y su esquema compositivo, ya que tales prácticas no se dan de manera tan entremezclada (Fig. 9). 
Figura 9 - Fachada interior norte

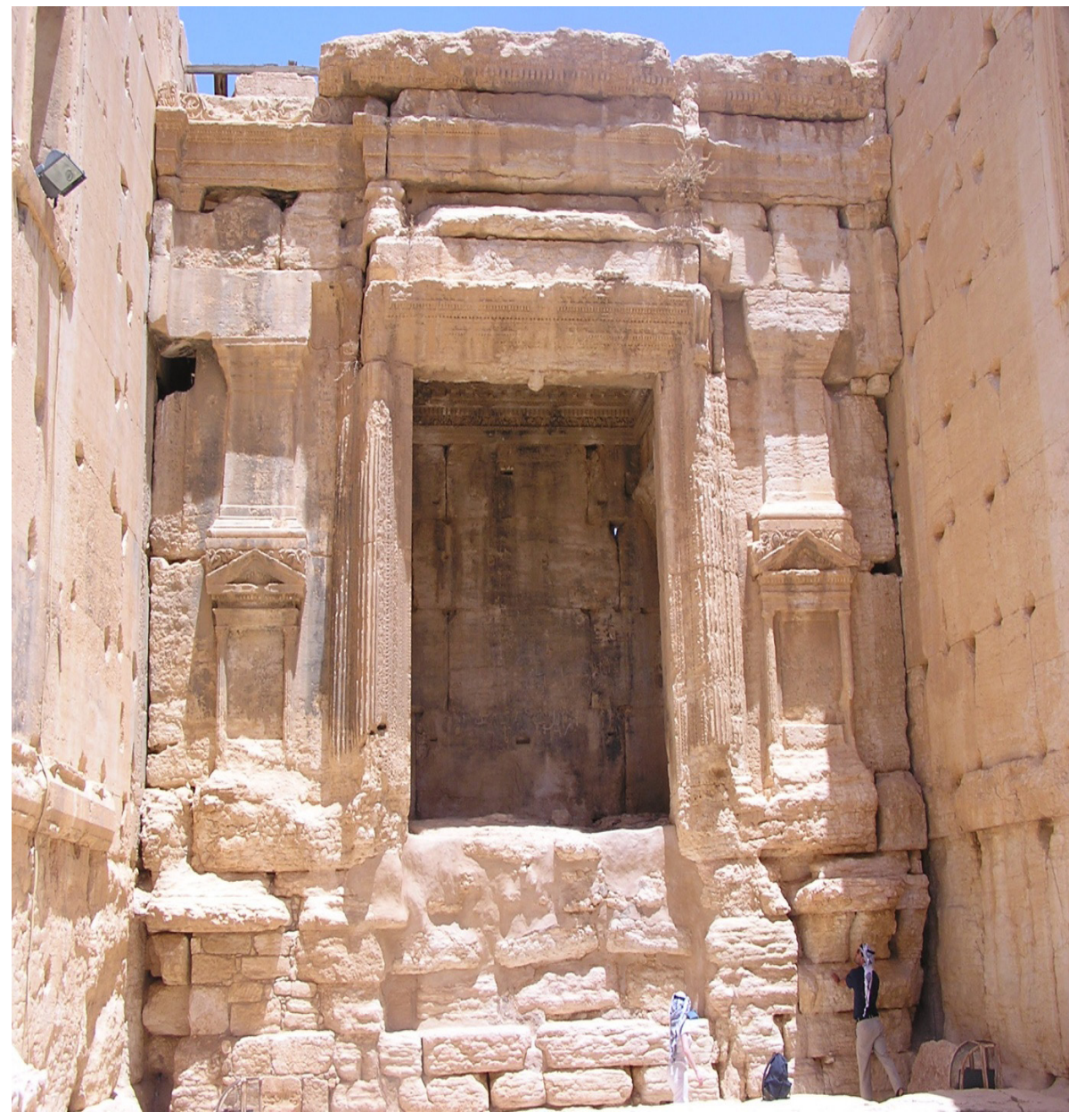

Fuente: Cortesía de Jorge García Sánchez.

Pasando ahora a examinar el tálamo sur, se ve que a primera vista tuvo una decoración y un entramado más sencillo que el norte. En su pared lisa sobresalían únicamente 4 semi-columnas que se adosaban al muro y sostenían el entablamento y el vano central. Además, un cuarto de columna se adosaba en cada rincón. De nuevo, siguiendo el esquema del tálamo norte, se aprecia una elevación sobre plinto de las columnas adosadas al muro, lo que motiva una falta de armonía vertical debido a la adhesión de esos cuartos de columnas que desproporcionan la representación (AMY, 1950, p. 100) y romper cualquier tipo de esquema modular que solían guardar los planteamientos decorativos de los templos romanos siguiendo los cánones vitrubianos.

El centro del techo del tálamo, a diferencia de los motivos figurativos del tálamo norte, está decorado con un motivo floral que recuerda a una rosa y motivos geométricos. Éste, a diferencia del norte, no tiene una sala anexa, aunque disponía de dos estructuras de escaleras, una cuadrada y otra cilíndrica, que darían paso a las estructuras de la terraza 
superior del templo. Estas escaleras y la tercera del tálamo norte tenían 17 escalones de idéntico tamaño (HAMMAD, 2005, p. 39).

La generalización de la arquitectura en piedra es una característica que también se puede asociar a los templos orientales y quizás también a los norteafricanos. Los templos provinciales de la parte occidental del Imperio, a excepción de los templos itálicos republicanos y los de la caput mundi, se hicieron mayoritariamente en ladrillo estucado o recubierto de lastras pétreas (pero no bloques) que intentaban aparentar mayor magnificencia de la que en verdad tenía. En los casos sirios la piedra trabajada con una cuidada estereotomía está dispuesta a soga, de nuevo una característica regional, tal y como vemos en los templos de Baalbek o Baetocece, por citar un par de ejemplos.

La entrada principal no está centrada en la fachada, ya que está condicionada por un elemento del templo previo. Su vano está perfectamente orientado a la fuente de Efqa (cuyo manantial se encuentra a 10 metros del suelo natural y en ella se encontró una escalera monumental tallada en la roca, exvotos y altares, HAMMAD, 2005, p. 59), algo que, aunque Amy postuló como casual, no lo es, y hay que valorar el papel de los cultos semíticos con la naturaleza (PRADOS, 2008, p. 144). El resto del conjunto que queda inscrito en el témenos, también es interesante de analizar. Hay dos accesos: el principal, al cual se accede desde unos propileos monumentales, y un pasaje alternativo en rampa que permitiría el acceso de carros y animales para el sacrificio hasta el mismo templo (KAIZER, 2002, p. 67). También hay que advertir la presencia de un altar monumental, una base de abluciones, una sala de banquetes y un edículo con un nicho de interpretación indeterminada. Es fácil de identificar un eje Este-Oeste que va articulando todos estos elementos a su llegada al templo dándonos una relación simétrica del espacio, aunque luego el templo no tenga enteramente un eje axial, el cual sólo se encuadra con el témenos. Como última pero interesante referencia, es interesante destacar la presencia de una base de estatuas con una inscripción que fue por primera vez documentada en el interior del templo pero que muchos autores sitúan que su contexto original habría sido el témenos y que sería el primer testimonio de dominio romano, ${ }^{14}$ datada en el 45 d.C. (KAIZER, 2002, p. 69-71; DIRVEN, 2011, p. 154). Si bien, no se puede hablar aún de culto imperial en la ciudad, la presencia de una estatua del descendiente de Druso y de Germánico motivaría cierto halo suprahumano y vislumbra el interés de la política provincial por situarse en la compleja religiosidad palmirana.

\footnotetext{
${ }^{14}$ [Dr]uso Caesari; Ti. Caesari, divi Aug f., Augusto, divi luli nepoti; Ge[rmanico caesari] / mperatoribus posuit/ [Min]ucius T. f., Hor., Rufus, legatus leg. X Fretensis (DIRVEN, 2011, p. 154) Dirven en este artículo analiza las implicaciones del culto imperial en la ciudad de Palmira, en muchas ocasiones vinculándose de uno u otro modo con el templo de Bel al ser uno de los santuarios más importantes de la ciudad e integrándose en la vida civil y religiosa de la ciudad.
} 
En una interpretación semiológica del templo, habría que entender el complejo sacro como una serie de espacios circunscritos uno dentro del otro que van marcando jerarquías y limitación de accesos (HAMMAD, 2005). Siguiendo este esquema, en realidad se podrían advertir tres espacios: el períbolo que da paso al pórtico y éste a su vez a la cella. Dicha interpretación correspondería con la de un centro de peregrinación como era el templo de Bel.

Se han postulado varias hipótesis sobre cómo se sufragaron los costes de construcción del templo. Pudo ser una conjunción de fieles devotos que regalaron algunas columnas (de ahí que en algunas partes de la columnata y en algunos templos se esculpan relieves como forma evergética) (VEYNE, 2009, p. 231). Otra opción es que dicho templo se sufragara por los ingresos del propio tesoro del templo. Una última hipótesis podría ser que un miembro de la familia imperial, príncipe o inclusive emperador, poniendo la mirada en Germánico durante su viaje a Oriente, podría haber regalado dicho templo a la ciudad (COLLEDGE, 1976, p. 220). La última hipótesis, a mi parecer, es descartable ya que dicho templo está lejos no sólo en el canon, sino con respecto a la incorporación de elementos arquitectónicos y decorativos no romanos, cosa que no es propia de un arte aúlico. Un ejemplo de arquitectura áulica por donación directa es el templo de Garni en Armenia, que se piensa que fue un regalo directo de Nerón. Lo que sí está claro es que los templos y columnatas fueron un muestrario del lujo y la riqueza que alcanzó Palmira (BOUNNI, 1985, p. 280-285).

El templo fue un proyecto de muy larga duración tanto en ejecución como en la preparación previa (HAMMAD, 2005, p. 31). Además, hay que tener en cuenta la existencia de estructuras anteriores como un antiguo témenos más reducido y orientado de otra forma, encontrado en las excavaciones que dirigió Seyrig así como unas bases de columna encontradas en las excavaciones de Bounni que inducen a pensar en un templo anterior de época seléucida.

\section{Algunos apuntes finales}

El proyecto arquitectónico del templo de Bel en la acrópolis de Palmira revela una consecución híbrida y una manera de mantener ciertas garantías que se adecuasen a la generalidad romana, pero conservando su intrínseco pasado que permitiera mantener su propio carácter y tradición. Esto, sin duda, entra dentro de un juego de políticas a caballo entre los dos mundos que, más allá de la propia casuística de Palmira, guarda directa relación con planteamientos arquitectónicos y estrategias de otros templos dispersos por la geografía sirio-romana (como, por ejemplo, en Baalbek) (ESPAÑA- 
CHAMORRO, 2015) y que mantuvieron igualmente la influencia de la arquitectura helenística desarrollada bajo el dominio seléucida sin perder el uso de elementos de culto semíticos que preservaban su carácter sacro.

La anexión de Siria como provincia romana supuso la implementación de modelos de arquitectura pública combinados con componentes prerromanos debido a la continuación con los cultos semíticos, determinando reinvenciones y reconversiones de los cánones constructivos en elementos híbridos insertos en el llamado tercer espacio donde colonos y colonizados acaban influyéndose recíprocamente.

Los encuentros coloniales que se hicieron patentes en Palmira como punto de paso entre de las grandes caravanas entre la costa mediterránea y el Imperio Parto, como zona de intercambios mercantiles que llevaron a una confluencia cultural, no supusieron ninguna traba en la inserción de esta área en la administración romana. A pesar de la revuelta de Zenobia en el siglo III, que lejos de entrar en los objetivos de la misma (HIDALGO DE LA VEGA, 2017), no hubo movimientos reivindicativos de carácter étnico, como por el contrario sí había ocurrido en Judea o en Grecia. Así, en Palmira se canalizaron sus influencias semitas, arameas, árabes e incluso partas, para desarrollar una hibridación cultural en los confines del Imperio que sería visible en sus manifestaciones culturales.

De igual modo, el proceso de cambio cultural y asimilación al sistema administrativo imperial fue el punto de partida para, una vez más, reinventar las artes, cambiar la mentalidad y adaptar la religión a la latinidad, pero sin perder su esencia. Palmira, que ha sido definida como "extranjera por su pasado" (VEYNE, 2009, p. 237) y a caballo entre dos mundos, el parto y el romano, se entremezcla en una provincia donde los cambios culturales no eran ni nuevos ni extraños. Siria y Palmira como zona de paso, dejaba lugares como Baalbek, los templos del Monte Hermón o los templos de Hauran como referentes de una mezcolanza de aspectos sincréticos con fuerte carácter sacro que se funden de manera difusa en donde la conciencia étnica no desaparece (SARTRE, 1994).

No hay que obviar el carácter romano en la zona a pesar de que se haya propuesto una mayor influencia helenística de Asia Menor y Alejandría (LYTTELTON, 1988, p. 142). Las tradiciones semíticas son toleradas por la administración romana, poder político armonizado con los poderes fácticos. Lo que sucede es que los santuarios enarbolan el carácter semítico de sus cultos y su cultura siria, no ya como una identidad propia y autónoma enfrentada al imperialismo romano y en confrontación con los cánones helenísticos, sino como un vehículo de expresión contemporánea (BUTCHER 2003; 2011).

En todo ello, el templo de Bel en Palmira sirve como ejemplo de estas confluencias culturales y su diseño arquitectónico y soluciones propias responden a una adaptación 
de las necesidades espaciales y arquitectónicas, así como de la adaptación al culto local (LOHMANN, 2010, p. 29), pero inmerso en las corrientes edilicias romanas.

Como anotación final, me gustaría traer una curiosa inscripción encontrada en la vecina provincia de Arabia, más concretamente en Ouab-elMouketteb, que evoca muy bien al punto en el que los procesos de hibridación de la región supusieron confusión y malestar a romanos de la otra punta del Imperio. Esta inscripción se disponía en una roca emplazada en un lugar de tránsito y seguramente fue hecha por un soldado romano o bizantino, ${ }^{15}$ en donde maldice la raza siria, adivinando pues que la estancia de los romanos de la parte occidental y de Grecia no era demasiado agradable al no poder compartir con las poblaciones locales tan si quiera la lengua de un modo generalizado. Esto demuestra que las lenguas, pero también la religión y otras muchas pautas culturales prerromanas que mantenían generaban la propia identidad íntima del mundo sirio, donde, a ojos de un ciudadano romano de occidente, aquello no entraba dentro de sus percepciones culturales, pero seguramente a ojos de un sirio, su inserción en el mundo romano sería innegable.

\section{Bibliografía}

\section{Primaria}

CORPUS INSCRIPTIONUM LATINARUM: v. X. Inscriptiones Bruttiorum, Lucaniae, Campaniae, Sicilae, Sardiniae latinae. Edidit par Theodorus Mommsen. Berlim: W. de Gruyter, 1883.

\section{Secundaria}

AMY, R. Temples à escaliers. Syria, v. 27.1, p. 82-136, 1950.

BAUDINI, A. Ellenismo e Oriente Romano: città a confronto in un'unità solo aparente. Bollettino di Archeologia on line, volume speciale, p. 55-60, 2010.

BALL, W. Rome in the East: the transformation of an Empire. London: Routledge, 2001.

BOËTHIUS, A.; LING, R.; RASMUSSEN, T. Etruscan and Early Roman Architecture. Atlanta: Yale University Press, 1978.

BOUNNI, A. Palmyra: the caravan city. Ebla to Damascus. Art and Archaeology of Ancient Syria, p. 380-285, 1985

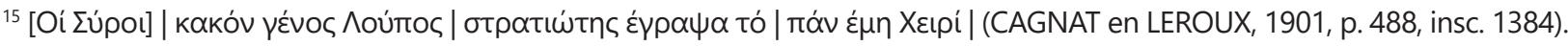


BOWERSOCK, G.W. Syria under Vespasian. Journal of Roman Studies, v. 63, p. 133-140, 1973.

BROWN, D. F. The hexagonal court at Baalbek. American Journal of Archaeology, v. 43.2, p. 285-288, 1939.

BUTCHER, K. Roman Syria and the Near East. London: The British Museum Press, 2003.

BUTCHER, K. Contesting sacred space in Lebanese temples. In: GRUEN, E. (Ed.) Cultural identity in the Ancient Mediterranean. Los Angeles: Getty Research Institute, 2011, p. 453-463.

CESCHI, C. Barroco romano d'Oriente e barroco italiano del Seicento. Genova: Bozzo \& Coccarello, 1941.

COLLEDGE, M. A. R. The art of Palmyra. London: Thames and Hudson, 1976.

DE JONG, L. Narratives of Roman Syria: a historiography of Syria as a province of Rome. Stanford Working Papers in Classics, 2007 Disponível em: https://papers.ssrn.com/ sol3/papers.cfm?abstract_id=1426969. Acesso em: 17 abr. 2019.

DIRVEN, L. Religious frontiers in the Syrian Mesopotamian desert. In: HEKSTER, O.; KAIZER, T. (Ed.). Frontiers in the Roman World. Leiden: Brill, 2011, p. 157-174.

ESPAÑA-CHAMORRO, S. Confluencias culturales en la Siria romana a través de la decoración arquitectónica del templo de Júpiter en Heliópolis (Baalbek, Líbano). In: GARCÍA SÁNCHEZ, J.; MAÑAS ROMERO, I.; SALCEDO GARCÉS, F. (Ed.). Navigare necesse est: estudios en homenaje a José María Luzón Nogué. Madrid: UCM, 2015, p. 135-144.

HAMMAD, M. Santuário de Bel em Tadmor/Palmira: ensaio de interpretação semiótica. Galáxia, v. 5, n. 9, p. 61-65, 2005.

HEIDEGGER, M. Construir, habitar, pensar. Teoría, n. 5-6, p. 150-162, 1951.

HIDALGO DE LA VEGA M.J. Zenobia, reina de Palmira: historia, mito y tradiciones. Florentia Iliberritana, v. 28, p. 79-104, 2017.

JIMÉNEZ DÍEZ, A. Imagines hibridae: una aproximación postcolonialista al estudio de las necrópolis de la Bética. Madrid: CSIC, 2018.

JIMÉNEZ DÍEZ, A. Pure hybridism: Late Iron Age sculpture in southern Iberia. World Archaeology, v. 43.1, p. 102-123, 2011.

KAIZER, T. The religious life of Palmyra: a study of the social patterns of worship in the Roman period. Stuttgart: Franz Steiner Verlag, 2002.

KAIZER, T. Man and God at Palmyra: sacrifice, lectisternia and banquets. In: (Ed.). The variety of local religious life in the Near East in the Hellenistic and Roman periods. Leiden: Brill, 2008, p. 179-192. 
LEROUX, E. (Ed.) Inscriptiones graecae ad res romanas pertinentes avctoritate et impensis. Paris: Academiae inscriptionvm et litterarvm hvmaniorvm collectae et editae, 1901. LOHMANN, D. Giant strides towards Monumentality - the Architecture of the Jupiter Sanctuary in Baalbek/Heliopolis. Boletino di Archeologia online, v. espeziale, p. 2229, 2010.

LYTTELTON, M. La arquitectura barroca en la Antigüedad Clásica. Ávila: Akal, 1988.

MAÑANA, P. Arquitectura como percepción. Arqueología de la Arquitectura, v. 2, p. 177$183,2003$.

MARCUS, M. I. Centre, province, and periphery: a new paradigm from Iron-Age Iran. Art History, v. 13, n. 2, p. 129-50, 1990.

MILLAR, F. The Roman Near East, 31 BC-AD 337. Cambridge: Harvard University Press, 1993.

PANE, R. Architectura barocca antica. Rassegna di architectura, v. VII, p. 37-41, 1935.

PRADOS, F. Arquitectura púnica: los monumentos funerarios. Madrid: CSIC, 2008.

REY-COQUAIS, J. P. Syrie romaine, de Pompée à Diocletien. Journal of Roman Studies, v. 68, p. 45-73, 1978.

RICHARDSON, P. City and Sanctuary: religion and architecture in the Roman Near East. London: SCM Press, 2002.

RICHMOND, I. A. Palmyra under the Aegis of Rome. Journal of Roman Studies, v. 53, p. 43-54, 1963.

SARTRE, M. El Oriente romano: provincias y sociedades provinciales del Mediterraneo oriental, de Augusto a los Severos (31 a.de C.-235). Madrid: Akal, 1994.

SEGAL, A. Religious architecture in the Roman Near East: temple of the basalt lands (Trachon and Hauran). In: KAIZER, T. (Ed.). The variety of local religious life in the Near East in the Hellenistic and Roman periods. Leiden: Brill, 2008, p. 97-133.

SEYRIG, H. Bas-reliefs monumentsux du temple de Bêl a Palmyre. Syria, v. 15, p. 184-185, 1934.

SEYRIG H. Heliopolitana. Bulletin du Musée de Beyrouth, v. 1, p. 77-100, 1937.

SEYRIG, H. Palmyra and the East. Journal of Roman Studies, v. 50, p. 1-7, 1950.

SEYRIG, H. Antiquités siyrennes: 57. Questions héliopolitaines. Syria, v. 31, n. 1-2, p. 68-98, 1954.

STAMPER, J.W. The architecture of Roman temples: the Republic to the Middle Empire. New York: Cambridge University Press, 2008.

TAYLOR, J. Petra. Amman: Al-Uzza Books, 2005.

TAYLOR, G. The Roman temples of Lebanon. Beirut: Librairie Orientale, 1986. 
VANDOMMELEN, P.Colonial constructs: colonialism and Archaeology in the Mediterranean. World Archaeology, v. 28. n. 3, p. 305-323, 2007.

VEYNE, P. El Imperio Grecorromano. Madrid: Akal, 2009.

WARD-PERKINS, J. B. Arquitectura romana. Madrid: Aguilar ediciones, 1976.

WIEGAN, T. Palmyra- Ergebnisse der expeditionen von 1902 und 1917. Berlin: Verlarg Heinrich Keller, 1932.

WILL, E. De l'Euphrate au Rhin: aspects de l'hellénisation et de la romanisation du ProcheOrient. Beyrouth: IFPO, 1995.

WOLFFLIN, H. Principles of art history: the problem of the development of style in later art. New York: Dover, 1950. 